\title{
Teorias da Propriedade, Entidade e Fundos: Uma Análise da Evidenciação das Demonstrações Financeiras de Empresas Sem Fins Lucrativos
}

\author{
Owner, Entity and Funds Theory: An Analysis of Financial Statements \\ Disclosure of Nonprofit Organizations \\ Raquel Nascimento Varandas \\ kelufv@yahoo.com.br \\ UFPR
}

\author{
Patricia Villa \\ patriciavilla00@gmail.com \\ UFPR
}

\author{
Romualdo Douglas Colauto \\ rdcolauto@ufpr.br \\ UFPR
}

\begin{abstract}
Resumo
As empresas sem fins lucrativos, para efeitos de evidenciação, são tratadas como empresas com fins lucrativos, obrigadas a publicar demonstrações financeiras que não transparecem efetivamente as informações que estas deveriam fornecer. Esta pesquisa tem o intuito de demonstrar a aplicação das teorias do proprietário, entidade e fundos em empresas sem fins lucrativos. A análise da aplicação destas teorias do patrimônio líquido foi testada em três organizações não governamentais, uma do Rio Grande do Sul, uma de Santa Catarina e uma do Paraná. Realizou-se uma pesquisa descritiva com as demonstrações contábeis das empresas estudadas podendo inferir desta pesquisa que as três teorias podem ser aplicadas em organizações sem fins lucrativos. O que difere é a visão de patrimônio líquido em cada uma das teorias elencadas. Neste intuito, a teoria dos fundos oferece a evidenciação mais perfeitamente aplicável ao Terceiro Setor.

Palavras-chave: empresas sem fins lucrativos, teoria da entidade, teoria do patrimônio, teoria dos fundos.

Abstract

Nonprofit organizations for disclosure purposes, are dealt as profit companies, required to publish financial statements that did not transpire effectively the information they should provide. This research aims to demonstrate the application of owner, entity and fund theory in nonprofit organizations. The analysis of the application of these theories was tested in tree organizations, one from Rio Grande do Sul, one from Santa Catarina and one from Paraná. A descriptive analysis in the financial statements of the companies was conducted in this research, and can infer that the tree theories can be applied for nonprofit organizations. What differs is the sight of equity in each of the listed theories. To this end, the fund theory provides more disclosure perfectly applicable to the Third Sector.
\end{abstract}

Key words: nonprofit organizations, owner theory, entity theory, fund theory.

Artigo recebido em: 19.04.2012; Aceito em: 31.05.2012 


\section{INTRODUÇÃO}

A contabilidade tem o papel de controlar e informar ao proprietário da riqueza, dos meios de produção, do seu estado patrimonial, e sua correspondente evolução. Com o surgimento das grandes corporações, a contabilidade teve um novo viés informativo, pois não havia mais a figura de proprietário dos ativos e passivos, mas o que importava era a própria sociedade enquanto centro de imputação de direitos e obrigações. A contabilidade passava a ter um novo destinatário das informações (ABE, 2007).

Esta descrição representa o momento que antecede o surgimento das Sociedades por Ações, a definição da Teoria da Entidade. Após, surgiu a Teoria da Propriedade, que defende o proprietário como destinatário das informações e possuidor de ativos e passivos, apresentando o conceito de firma, de sociedade, de entidade como sendo uma figura separada do proprietário. A Teoria dos Fundos mostra que o controle de uma organização deve ser realizado por meio de seus fundos, que para este conceito, deve ser da base da contabilidade.

Este estudo pretende demonstrar a aplicação das Teorias da Entidade, Propriedade e Fundos em entidades sem fins lucrativos. As empresas sem fins lucrativos, de acordo com Hansmann (1980) são empresas voltadas, principalmente, a atividades de educação, pesquisa, cuidados com a saúde, e são "organizações proibidas de distribuir sobre a forma financeira, seus superávits àqueles que a controlam”.

Estas empresas captam recursos, basicamente, por meio de solidariedade alheia, resultando muitas vezes em escassez dos mesmos. Estes recursos devem ser controlados de forma que as instituições obtenham um superávit no final do período, pois o objetivo destas instituições é de maximizar os benefícios gerados com os recursos arrecadados.

$\mathrm{Na}$ legislação brasileira, as organizações sem fins lucrativos obedecem aos mesmos princípios das organizações com fins lucrativos, sendo a evidenciação de suas demonstrações financeiras interpretadas conforme a teoria da entidade. No entanto, a maioria dos recursos captados pelas organizações sem fins lucrativos tem destinação específica, deste modo a teoria dos fundos pode ser considerada como a mais adequada para a evidenciação do patrimônio destas organizações (SANTANA et al, 2008).

Diante do exposto, esta pesquisa objetiva demonstrar a aplicação da teoria do proprietário, da entidade e dos fundos em empresas sem fins lucrativos, além de verificar qual das teorias apresenta melhor aplicação para cada uma das empresas analisadas.

A partir das explicações das intenções da pesquisa é possível formular a seguinte questão de pesquisa: Como operacionalizar a aplicação das teorias do patrimônio líquido elencadas (teoria do proprietário, entidade e fundos) às empresas sem fins lucrativos?

Este estudo se justifica diante da escassez de pesquisas nesta área, conforme demonstrado por Santana et al (2008), pois apesar de elevado grau de importância para o desenvolvimento da contabilidade, o patrimônio líquido é pouco estudado e suas teorias não estão sendo consideradas relevantes para o desenvolvimento da contabilidade.

Posteriormente, serão apresentados os conceitos de patrimônio líquido e das teorias do proprietário, da entidade e do fundo. Em um segundo momento será apresentada a metodologia aplicada na pesquisa e a análise dos dados colhidos. Por fim são apresentadas as considerações finais do estudo.

\section{REFERENCIAL TEÓRICO}

\subsection{Teorias dos Direito de Propriedade}


As teorias dos direitos de propriedade analisam essencialmente a participação do indivíduo na empresa. Para Hendriksen e Van Breda (2007: 464) cada uma das diversas teorias interpreta a posição econômica da empresa de maneira diferente, e apresenta assim uma ênfase distinta quanto ao método de divulgação dos interesses dos diversos portadores de títulos ou grupos interessados. Em geral mostram alternativas para reportar os elementos que compõem o Patrimônio Líquido, os quais estão intrinsecamente relacionados à mensuração dos ativos e passivos.

Ativos e Passivos, em sentido restrito, podem ser definidos e mensurados de forma independente, sendo o valor da diferença entre ambos o montante atribuído ao Patrimônio Líquido, o qual não representa o valor de mercado do Patrimônio Líquido nem o valor subjetivo da empresa para os proprietários de ações ou quotas, mas apenas o somatório dos resultados dos métodos empregados na mensuração de ativos e passivos (IUDÍCIBUS, 2010). Para Hendriksen e Van Breda (2007: 464) o patrimônio líquido não pode ser definido independentemente de ativos e passivos. Numa formulação mais geral, representa a diferença entre os recursos e as obrigações da entidade. O IASB (2001) afirma que o patrimônio líquido consiste na representação do interesse residual nos ativos da entidade depois de deduzir todos os seus passivos.

Abe (2007, p. 49) expõe que as definições do patrimônio líquido reiterando que independente da forma como se denomina, "é um elemento analisado pelos destinatários das informações contidas nas demonstrações contábeis, quer seja como demonstrativo de valor presente, quer seja como uma métrica de resultados futuros". E este entendimento é fundamental para a compreensão do patrimônio líquido que detém sua mensuração a partir da mensuração dos itens de ativo e de passivo pois, de acordo com a Estrutura Conceitual das Demonstrações Contábeis (CPC, 2008), "o valor pelo qual o Patrimônio Líquido é apresentado no Balanço Patrimonial depende dos método de mensuração de Ativos e Passivos".

Uma boa evidenciação dos elementos constitutivos do patrimônio liquido auxilia no discernimento dos interesses dos usuários, e a principal finalidade das demonstrações estará sendo cumprida. Isto é, ajudar o investidor a avaliar a continuidade do negócio (IUDÍCIBUS, 2010). Desta forma, a informação a ser transmitida deve refletir claramente os valores de resultado operacional da empresas e os ativos e passivos possuídos por esta.

E considerando-se que o patrimônio líquido é obtido da diferença dos valores atribuídos aos ativos e passivos é possível visualizá-lo por meio de diversas teorias: a teoria do proprietário, a teoria da entidade, a teoria do acionista ordinário, a teoria do fundo, a teoria do comando e a teoria do empreendimento.

A Teoria da Propriedade vê a corporação como um instrumento dos proprietários, ao invés de como uma entidade com vida própria separada dos acionistas (KAM, 1986), defendendo que o lucro que a empresa obtiver pertence ao proprietário. A Teoria da Entidade contrapõe este conceito, afirmando que empresa e proprietário têm vidas distintas, Hendriksen e Van Breda (2007) relatam que a teoria da Entidade precedeu o conceito de sociedade por ações, sendo que o lucro líquido representa uma variação residual do patrimônio após deduzir todos os outros direitos. Assim, só será lucro para os acionistas se o valor de mercado das ações incorporá-lo.

A teoria dos Direitos Residuais é citada por Straubus (1959) como sendo o meio do caminho entre a teoria da propriedade e teoria da entidade. Esta teoria defende o foco no acionista ordinário e todas as informações devem ser úteis para a tomada de decisões econômicas. Já na Teoria do Fundo, são abandonadas as relações pessoais que consubstanciam a teoria do proprietário e a personalização da firma como entidade legal e econômica artificial implícitas na teoria da entidade. O fundo é o núcleo de interesse (IUDÍCIBUS, 2010). 
A teoria do comando foi desenvolvida por Goldberg para que a contabilidade fosse controlada por seu gerente principal, e Iudícibus (2010, p. 170) complementa ainda que, nesta teoria, as demonstrações financeiras são feitas sob a forma de relatório de progresso.

A respeito da última teoria, Iudícibus (2010) define a teoria do empreendimento com foco na sociedade, considerada um centro de tomada de decisões que afeta as pessoas que dela participam, quer sejam acionistas, empregados, credores, consumidores ou órgãos governamentais. É também denominada teoria social do patrimônio.

\subsection{Teoria do Proprietário}

A noção de propriedade originou-se de uma tentativa de colocar alguma lógica na exposição da escrituração por partidas dobradas. Na equação contábil $\sum \mathrm{A}-\sum \mathrm{P}=\mathrm{PL}$, o proprietário situa-se na posição de principal interesse (HENDRIKSEN e VAN BREDA, 2007). Esta teoria prevê que os lucros líquidos, obtidos depois de descontadas as despesas das receitas originadas, seriam de posse dos proprietários e que os ativos são direitos dos proprietários e os passivos suas obrigações. O proprietário, então, é o centro das atenções da contabilidade.

Considerado como foco da contabilidade, o proprietário ainda pode ser visualizado como principal retentor dos lucros, pois, de acordo com Kam (1986) esta teoria ainda serve de base para grande parte das práticas contábeis, já que os dividendos ainda são considerados como distribuição de lucros e não como despesas da entidade.

Outra prática que retoma o lucro como sendo destinado diretamente ao proprietário é o método de equivalência patrimonial de avaliação de investimentos de uma sociedade, pois o resultado da sociedade investida pertence ao sócio investidor na medida em que o resultado seja apurado e qualquer alteração no patrimônio líquido da investida precisa ser reconhecida no patrimônio líquido da investidora (ABE, 2007).

Porém Kam (1986) conclui que do ponto de vista da tributação esta teoria é falha, pois o proprietário teria sua renda tributada duas vezes, no lucro societário e no recebimento deste lucro. Tal fato pode configurar dupla tributação, jurídica e econômica, a partir da premissa que ambas são consideradas como base para o imposto sobre a renda.

Diante do exposto, a afirmação de Iudícibus (2010) de que esta teoria adapta-se melhor às formas organizacionais mais simples, como a firma individual, é válida, pois neste caso a dupla tributação pode não se aplicar. E no entanto é distante da realidade imaginar, sob a ótica da responsabilidade limitada, que o proprietário assuma todas as dívidas de uma sociedade, se considerada uma firma de grande porte.

$\mathrm{Na}$ teoria da entidade, contudo, ocorre o oposto do anteriormente descrito, uma vez que sobressai a figura jurídica da sociedade e o proprietário é pessoa externa à esta forma jurídica.

\subsection{Teoria da Entidade}

Na teoria da entidade, a empresa é vista como tendo existência, ou mesmo personalidade, separada. Os fundadores e proprietários não são necessariamente identificados com a existência da empresa. Essa relação encontra apoio legal e institucional na sociedade por ações, mas também é encontrada em outras formas de organização de empresas. (HENDRIKSEN e VAN BREDA, 2007).

Ao estudar algumas teorias contábeis do século XIX, Littleton identificou que o capital era tratado como o total de ativos da propriedade, independente de sua fonte, ou seja, que 
empréstimos e investimentos de capital eram tratados pelos teóricos da época como fontes de capital, detalhados pelos ativos da sociedade (ABE, 2007). Obteve-se, então, um resultado pelo gerenciamento dos ativos que não seria afeto ao proprietário, mas à entidade, ou seja, o lucro é a razão para existência da empresa.

Deste modo Hendriksen e Van Breda (2007) definem que a teoria da entidade é baseada na equação: $\sum \mathrm{A}=\sum \mathrm{P}=\mathrm{PA}$, ou seja, Ativos = Direitos (Passivos mais Patrimônio de Acionistas). Estes autores consideram que a principal diferença entre passivos e direitos dos acionistas é de que os direitos dos credores podem ser avaliados independentemente de outros valores, sendo que estes credores possuem prioridade quando da apuração do exercício financeiro, e os lucros somente serão repassados aos acionistas após os cumprimentos das obrigações legais para com os credores.

Iudícibus (2010) complementa afirmando que o lucro do período apenas será lucro pessoal para os acionistas se o valor de mercado da ação reconhecê-lo ou incorporá-lo, mas isto está sujeito a muitas variáveis e incertezas.

Outra visualização desta teoria é sobre os passivos, que são as obrigações específicas da empresa, e os ativos, que representam os direitos da empresa de receber bens e serviços e outros benefícios específicos. A avaliação destes ativos, portanto, deve refletir a mensuração dos bens a serem recebidos pela empresa (HENDRIKSEN e VAN BREDA, 2007).

Resumindo-se, as hipóteses formuladas por Li apud Abe (2007, p. 59) sobre a teoria da entidade descrevem perfeitamente a lógica e finalidade desta teoria:

\footnotetext{
(a) objetivo primário de uma sociedade quando ela é incorporada é o de prestar serviços e criar utilidades; (b) a sociedade para atingir seus objetivos irá buscar recursos; (c) uma vez que a sociedade é um centro de imputação de direitos e obrigações, possui capacidade (no sentido jurídico) de contratar com os fornecedores de recursos; (d) após a sua incorporação, o principal objetivo da sociedade passa a ser o da sobrevivência; (e) com este novo objetivo, a sociedade busca atingir e manter competência econômica e financeira.
}

Com estes objetivos o autor descreveu o surgimento e a finalidade de uma empresa, empregando a fórmula anteriormente apresentada, onde os ativos se igualam aos credores mais os direitos dos acionistas. Ressalta ainda que a sociedade busca atingir e manter competência econômica e financeira, transparecendo uma gestão com foco na empresa e não no lucro pessoal do proprietário.

Iudícibus (2010, p. 169) remonta uma explicação de Paton e Littleton (1940) que foi corroborada pelas hipóteses de $\mathrm{Li}$, uma vez que foram formuladas anteriormente, "a ênfase no ponto de vista da entidade (...) requer o tratamento dos ganhos e lucros de negócio como lucro da entidade em si até que a transferência para os participantes individuais tenha sido feita por uma declaração de dividendos".

No momento em que os autores definem a forma pela qual a entidade repassará o lucro a seus proprietários, fica configurada a essência desta teoria, de que a empresa é uma entidade separada da figura do proprietário individual. E só obterá lucro se a empresa obtiver lucro e decidir distribuí-lo, diferentemente do princípio da Teoria do Proprietário de que o lucro da empresa é considerado lucro do investidor automaticamente.

\subsection{Teoria do Fundo}

A Teoria dos Fundos trata a empresa como uma unidade operacional, orientada para atividades, como base da contabilidade. Idealizada por W. J. Vatter em 1947, como uma extensão da Teoria da Entidade a base de tal teoria seria um grupo de ativos e um conjunto de 
atividades ou funções para as quais esses ativos são utilizados (ABE, 2007). Essa área de interesse, denominada fundo, inclui um grupo de ativos e obrigações e restrições correspondentes, representando funções ou atividades econômicas específicas (HENDRIKSEN e VAN BREDA, 2007).

Iudícibus (2010, p. 170) descreve que "o capital investido representa uma restrição financeira ou legal para o uso dos ativos, isto é, o capital investido precisa ser mantido intacto (...) os passivos (no sentido restrito) representam restrições contra ativos específicos ou gerais do fundo".

Hendriksen e Van Breda (2007) esclarecem que a teoria do fundo baseia-se na equação Ativos = Restrições sobre ativos. Esclarecem ainda que o conceito de fundo tem encontrado sua maior utilidade em instituições governamentais e sem fins lucrativos. Porém, Iudícibus (2010) afirma que no Brasil sua aplicação poderia ser notada em universidades ou outras entidades do gênero, nos quais os fundos são ligados a ativos específicos. Não cabendo, porém, aplicação na contabilidade governamental brasileira, que adota uma sistemática completamente diferente da norte-americana.

Conforme Vatter apud Abe (2007) todo resultado do uso de ativos, isto é, a diferença entre receitas e despesas deve ser distribuído como retribuição do financiamento das transações ou retido nas contas do então "patrimônio líquido". O autor afirma ainda que a teoria do fundo não procura medir para quem a renda é destinada (ABE, 2007).

Iudícibus (2010) esclarece que o lucro não é o ponto central da contabilidade, considerando-se esta teoria, e que a descrição das operações do fundo é realizada com muito detalhe e clareza, pois a demonstração que deve aparecer será de movimentação de fundo, com uma descrição dos fundos providos pelas operações. Esta demonstração difere bastante da demonstração de resultado do exercício pois, objetivam demonstrar o desenvolvimento dos fundos.

Hendriksen e Van Breda (2007) expõem que a teoria do fundo também pode ser utilizada por outras áreas, como áreas específicas de interesse dentro das sociedades por ações; como, por exemplo, fundo de amortização na contabilidade financeira, a contabilidade de filiais ou divisões e a contabilidade de espólios ou fundos administrados por agentes fiduciários.

\section{METODOLOGIA}

Quanto à abordagem do problema, a pesquisa caracteriza-se em qualitativa, com objetivo descritivo (SAMPIERI et al, 2006). Para realizar a análise entre as teorias do proprietário, entidade e fundos, foram selecionadas três organizações não governamentais dos três estados do sul do Brasil. A escolha das organizações deve-se às iniciativas de transparência, pois cada empresa traz acessos sobre suas atividades, código de ética e informações contábeis em seus sites.

A primeira empresa analisada foi a Parceiros Voluntários, uma Organização NãoGovernamental, sem fins lucrativos, apartidária, criada em janeiro de 1997 por iniciativa do empresariado do Rio Grande do Sul (PARCEIROS VOLUNTÁRIOS, 2011). Com a Missão de ser um movimento disseminador da cultura do voluntariado organizado no Brasil, visa pessoas, comunidades e uma sociedade mais solidária. A ONG lidera projetos e os programas de Voluntário Pessoa Física, Voluntário Pessoa Jurídica, Parceiros Jovens Voluntários e Organizações da Sociedade Civil.

A segunda empresa analisada foi a Casa da Criança, uma Organização Não-Governamental com sede em Florianópolis/SC. Fundada em 14 de março de 1988, esta associação civil sem fins lucrativos busca intervir na realidade social, evitando a violação dos direitos básicos das crianças e adolescentes, deixando à disposição da comunidade espaços físicos que possibilitem a formação de grupos de discussão e de elaboração de propostas que erradiquem 
a marginalização social, política e cultural dos menores residentes na comunidade (CASA DA CRIANÇA, 2011).

A última organização foi o Centro de Ação Voluntária, uma organização não governamental, sem fins econômicos que tem como principal objetivo estimular e fortalecer o voluntariado em Curitiba/PR e Região Metropolitana (CENTRO DE AÇÃO VOLUNTÁRIA, 2011).

Após a seleção das três organizações, buscou-se analisar seus demonstrativos financeiros e as notas explicativas, a fim de se elaborar os ajustes necessários para análise das três Teorias dos Direitos de Propriedade elencadas anteriormente. A partir dos dados dispostos nos sites das organizações, foi possível acessar informações como total do Ativo, Passivo e seus respectivos subgrupos, além dos componentes do Patrimônio Líquido. A disposição dos dados e os resultados estão dispostos a seguir.

\section{ANÁLISE DOS DADOS E DISCUSSÃO}

Este estudo buscou analisar os demonstrativos contábeis das três entidades mencionadas à luz das Teorias do Proprietário, da Entidade e dos Fundos. A respeito da Teoria do Proprietário, buscou-se separar as contas do Balanço Patrimonial em Ativo e Passivo, pois tal Teoria considera que o saldo desta equação é de posse do proprietário. A segunda Teoria, da Entidade, também analisa a equação Ativo menos Passivo, contudo, a diferença é que o saldo, ou seja, o Patrimônio Líquido, é de posse da Entidade, e não mais de uma pessoa somente.

Já a Teoria dos Fundos foi utilizada neste artigo para verificar se sua aplicação está de acordo em empresas sem fins lucrativos. Para tanto, tomou-se por base o Pronunciamento SFAS 117 (in SANTANA et al, 2008), do American Institute of Certified Public Accountants (AICPA, 1993). Tal pronunciamento buscou tratar especificamente dos procedimentos contábeis para organizações sem fins lucrativos.

Para o SFAS 117, os recursos básicos arrecadados pelas instituições originam-se de três categorias diferentes:

(1) recebidos sem nenhuma restrição (uso irrestrito): permite a direção/gestores utilizarem os recursos doados/recebidos da forma como lhe convier, desde que cumprido os objetivos da organização;

(2) recebidos com restrições temporárias: quando do recebimento dos recursos, os doadores impõe uma restrição do uso destes, obrigando à instituição utilizá-los como especificado, e que é cumprida pelo tempo decorrido ou por ações da instituição;

(3) recebidos com restrições permanentes: quando do recebimento dos recursos, os doadores impõem restrições limitando a utilização destes somente em consonância com as determinações do doador.

Segundo Santana et al (2008), este tipo de contabilização vem dar mais transparência a evidenciação das informações contábeis nas demonstrações financeiras das instituições, visto que os usuários dos demonstrativos necessitam identificar como foi ou até mesmo como estão sendo realizadas as aplicações destes recursos e qual o resultado final alcançado pela organização de forma segregada por origem de fundos.

Os tópicos a seguir indicam a aplicação das três Teorias elencadas nas empresas selecionadas. Os demonstrativos utilizados foram o Balanço Patrimonial e a Demonstração do Resultado do Exercício, disponibilizados pelas três empresas.

\subsection{Demonstrativos iniciais e aplicação das Teorias - ONG Parceiros Voluntários}

Os Quadros 01 e 02 representam, respectivamente, o Balanço Patrimonial e a Demonstração do Resultado do Exercício da ONG Parceiros Voluntários, para o ano de 2010. 


\begin{tabular}{|c|c|}
\hline ATIVO (Reais) & 2.010 \\
\hline Circulante & 2.013.794 \\
\hline Caixa e equivalentes de caixa & 1.848 .141 \\
\hline Outros créditos & 165.316 \\
\hline Despesas antecipadas & 337 \\
\hline Não circulante & 2.234 .365 \\
\hline Realizável a longo prazo & \\
\hline Fundo de sustentabilidade & 1.594 .439 \\
\hline Depósitos judiciais & 20.199 \\
\hline Imobilizado & 92.119 \\
\hline Intangível & 527.608 \\
\hline Total do Ativo & 4.248.159 \\
\hline PASSIVO (Reais) & 2.010 \\
\hline Circulante & 1.253.187 \\
\hline Fornecedores & 4.818 \\
\hline Salários e encargos sociais & 99.855 \\
\hline Obrigações fiscais & 17.404 \\
\hline Receitas diferidas - projetos & 1.117 .955 \\
\hline Outras contas a pagar & 13.155 \\
\hline Não circulante & 21.989 \\
\hline Obrigações sociais & 21.989 \\
\hline Patrimônio social & 2.972.983 \\
\hline Reserva de doações & 79.760 \\
\hline Reservas - fundo sustentabilidade & 1.500 .000 \\
\hline Ajuste de avaliação patrimonial & 27.202 \\
\hline Superávits acumulados & 1.366 .021 \\
\hline Total Passivo e PL & 4.248.159 \\
\hline
\end{tabular}

Fonte: adaptado de Parceiros Voluntários (2011).

O Quadro 01 demonstra que a ONG possui uma conta em seu Ativo Não Circulante chamada Fundo de Sustentabilidade. Tal conta possui contrapartida no Patrimônio Social, como Reservas - Fundo de Sustentabilidade. Conforme informações em notas explicativas, contempla recursos recebidos de mantenedores com o objetivo de prover as necessidades de caixa em decorrência de obrigações futuras que possam vir a ser assumidas pela organização. Outra característica da ONG é a rubrica de Superávits acumulados, no grupo do Patrimônio Social, formado pelas receitas e despesas da entidade, demonstradas no Quadro 02. 
Quadro 02 - Demonstração do Resultado do Exercício - ONG Parceiros Voluntár
\begin{tabular}{|l|c|}
\hline \multicolumn{1}{|c}{ Operações continuadas (Reais) } & $\mathbf{2 . 0 1 0}$ \\
Receitas das atividades operacionais & $\mathbf{3 . 0 5 3 . 7 5 4}$ \\
Contribuições de mantenedores & 1.094 .303 \\
Projetos e eventos de assessoramento & 1.959 .451 \\
Despesas das atividades operacionais & $\mathbf{( 3 . 1 3 0 . 2 6 7 )}$ \\
Projetos de assessoramento & $(1.436 .404)$ \\
Gerais e administrativas & $(1.693 .863)$ \\
Déficit operacional antes do Resultado financeiro & $\mathbf{( 7 6 . 5 1 3 )}$ \\
Resultado financeiro & \\
Resultado financeiro líquido & 301.286 \\
Superávit do exercício & $\mathbf{2 2 4 . 7 7 3}$ \\
\hline
\end{tabular}

Conforme o Quadro 02, nota-se que a entidade adquire receitas de doações de mantenedoras e de projetos de assessoramento, como os Programas de Sustentabilidade, Transparência e Formação de Gestores Sociais, que a ONG gerencia.

A aplicação da Teoria do Proprietário, no caso desta ONG, indica que o valor mencionado no Patrimônio Social, demonstrado na Tabela 01, seria uma posse dos proprietários, conforme esta Teoria. Contudo, como a entidade é uma Organização Não-Governamental, sem fins lucrativos, a questão recai sobre quem seria o proprietário do Patrimônio da empresa. Pode-se inferir que, por ser uma ONG, o "proprietário" seria a sociedade, ou, mais especificamente, seus beneficiários mais próximos.

Tabela 01 - Teoria do Proprietário - ONG Parceiros Voluntários (em Reais)

\begin{tabular}{l|r|l|r}
\hline ATIVO & $\mathbf{4 . 2 4 8 . 1 5 9 , 0 0}$ & PASSIVO & $\mathbf{1 . 2 7 5 . 1 7 6 , 0 0}$ \\
\hline Circulante & $2.013 .794,00$ & Circulante & $1.253 .187,00$ \\
Não Circulante & $2.234 .365,00$ & Não Circulante & $21.989,00$ \\
ATIVO - PASSIVO $=$ & $2.972 .983,00$ & (PROPRIETÁRIO) & \\
\hline
\end{tabular}

Fonte: elaborado pelos autores.

A Tabela 02 representa a Teoria da Entidade na ONG Parceiros Voluntários. Neste caso, a mesma configuração clássica da Teoria Contábil é apresentada, e afirma-se que a empresa possui continuidade e personalidade próprias, independente de seus dirigentes.

Tabela 02 - Teoria da Entidade - ONG Parceiros Voluntários (em Reais)

\begin{tabular}{l|r|l|r}
\hline ATIVO & $\mathbf{4 . 2 4 8 . 1 5 9 , 0 0}$ & PASSIVO & $\mathbf{1 . 2 7 5 . 1 7 6 , 0 0}$ \\
\hline Circulante & $2.013 .794,00$ & Circulante & $1.253 .187,00$ \\
Não Circulante & $2.234 .365,00$ & Não Circulante & $21.989,00$ \\
& & PATRIMÔNIO LÍQUIDO & $\mathbf{2 . 9 7 2 . 9 8 3 , 0 0}$ \\
\hline
\end{tabular}

Fonte: elaborado pelos autores. 
A Tabela 03 representa os valores do Balanço Patrimonial da ONG Parceiros Voluntários, alocados conforme a Teoria dos Fundos. Considerou-se como Uso Irrestrito as rubricas que não possuíam destinação específica, conforme informações em Notas Explicativas. Já as contas de Uso Internamente Restrito representam os valores que serão alocados somente em imobilizados da empresa, ou em atividades de cunho social, tais como os projetos geridos pela organização. Já a coluna de Uso Externamente Restrito representa as ações de Sustentabilidade da empresa, que contempla recursos recebidos de mantenedores com o objetivo de prover as necessidades de caixa em decorrência de obrigações futuras que possam vir a ser assumidas pela organização.

Tabela 03 - Teoria dos Fundos - ONG Parceiros Voluntários (em Reais)

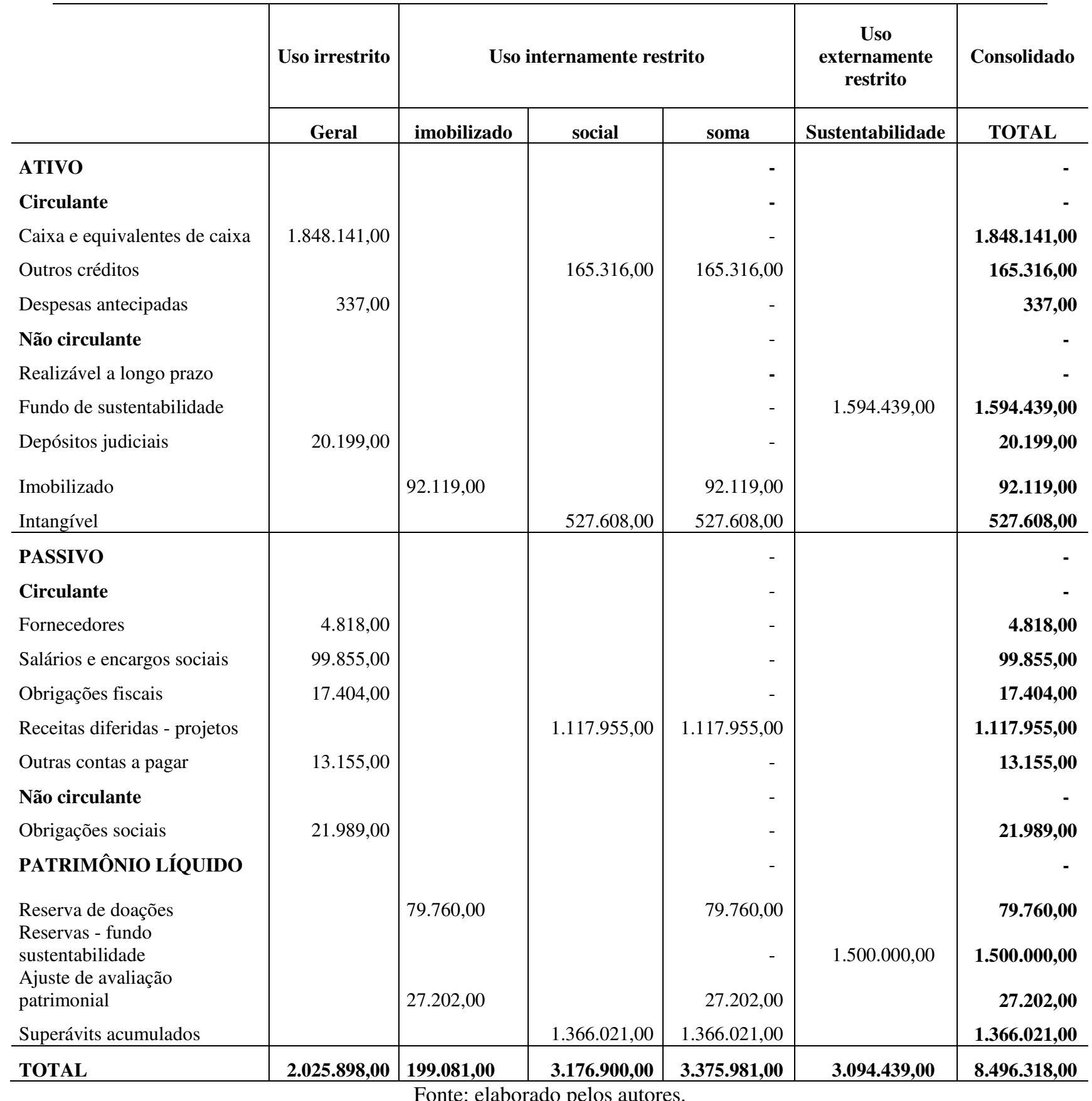




\subsection{Demonstrativos iniciais e aplicação das Teorias - ONG Casa da Criança}

O Quadro 03 representa o Balanço Patrimonial da ONG Casa da Criança, para o ano de 2010.

\begin{tabular}{|c|c|}
\hline ATIVO (Reais) & 2.010 \\
\hline Circulante & $78.919,65$ \\
\hline Caixa e equivalentes & $72.870,88$ \\
\hline Direitos Realizáveis a Curto Prazo & $4.205,71$ \\
\hline Estoque de materiais para bazar & $1.843,06$ \\
\hline Não Circulante & $365.037,71$ \\
\hline Imobilizado & $365.037,71$ \\
\hline Edifícios & $295.204,25$ \\
\hline Biblioteca & $26.474,95$ \\
\hline Computadores e Periféricos & $18.866,66$ \\
\hline Instalações & $11.639,83$ \\
\hline Máquinas e Equipamentos & $37.201,86$ \\
\hline Móveis e utensílios & $18.566,99$ \\
\hline Terrenos & $60.000,00$ \\
\hline (-) Depreciação Acumulada & $-102.916,83$ \\
\hline Total do Ativo & 443.957,36 \\
\hline PASSIVO (Reais) & 2.010 \\
\hline Circulante & $3.844,46$ \\
\hline Salários e Ordenados a Pagar & 770,70 \\
\hline Obrigações Tributárias & $1.766,35$ \\
\hline Outros créditos & $1.307,41$ \\
\hline Patrimônio Líquido & $440.112,90$ \\
\hline Patrimônio social efetivado & 642,22 \\
\hline Doações Patrimoniais & $34.599,61$ \\
\hline Reserva de reavaliação & $180.623,84$ \\
\hline Superávit do exercício & $31.455,69$ \\
\hline Superávit ou Déficit Exerc. Anteriores & $192.791,54$ \\
\hline Total Passivo e PL & 443.957,36 \\
\hline
\end{tabular}

O Quadro 03 mostra que a ONG Casa da Criança possui uma conta em seu Ativo Circulante chamada Estoques de materiais para bazar, representado os valores que estão alocados na função social da entidade. A ONG não apresentou Demonstração do Resultado do Exercício 
para o ano de 2010 em seu site, o que não dificultou a análise, mas prejudicou a geração de informações mais precisas.

Para a Teoria do Proprietário, os lucros líquidos, obtidos depois de descontadas as despesas das receitas originadas, seriam de posse dos proprietários. Da mesma forma, os ativos são direitos dos proprietários e os passivos suas obrigações. O proprietário, então, é o centro das atenções da contabilidade. No caso da ONG Casa da Criança, conforme a Tabela 04, o valor indicado representa os recursos que a entidade possui a disposição dos proprietários.

Tabela 04 - Teoria do Proprietário - ONG Casa da Criança (em Reais)

\begin{tabular}{l|r|l|r}
\hline ATIVO & $\mathbf{4 4 3 . 9 5 7 , 3 6}$ & PASSIVO & $\mathbf{3 . 8 4 4 , 4 6}$ \\
\hline Circulante & $78.919,65$ & Circulante & $3.844,46$ \\
Não Circulante & $365.037,71$ & Não Circulante & 0,00 \\
ATIVO - PASSIVO $=$ & $440.112,90$ (PROPRIETÁRIO) \\
\hline
\end{tabular}

Fonte: elaborado pelos autores.

Já a Teoria da Entidade afirma que a empresa é vista como tendo existência, ou mesmo personalidade, separada. Os fundadores e proprietários não são necessariamente identificados com a existência da empresa. Essa relação encontra apoio legal e institucional na sociedade por ações, mas também é encontrada em outras formas de organização de empresas. A Tabela 05 mostra a configuração do Balanço no caso da Teoria da Entidade para a ONG Casa da Criança.

Tabela 05 - Teoria da Entidade - ONG Casa da Criança (em Reais)

\begin{tabular}{l|r|l|r}
\hline ATIVO & $\mathbf{4 4 3 . 9 5 7 , 3 6}$ & PASSIVO & $\mathbf{4 4 3 . 9 5 7 , 3 6}$ \\
\hline Circulante & $78.919,65$ & Circulante & $3.844,46$ \\
Não Circulante & $365.037,71$ & Não Circulante & 0,00 \\
& & PATRIMÔNIO LÍQUIDO & $\mathbf{4 4 0 . 1 1 2 , 9 0}$ \\
\hline
\end{tabular}

Fonte: elaborado pelos autores.

A Tabela 06 representa os valores alocados conforme a Teoria dos Fundos para a ONG Casa da Criança. Considerou-se como Uso Irrestrito as rubricas que não possuíam destinação específica, conforme informações em Estatuto Social. Já as contas de Uso Internamente Restrito representam os valores que serão alocados somente em imobilizados da empresa, ou em atividades de cunho social, como os projetos geridos pela organização. Já a coluna de Uso Externamente Restrito representa as doações de recursos que a empresa recebeu e que está destinado diretamente em seu Patrimônio Líquido. A disposição do Superávit na coluna de Uso internamente Restrito - Social, deve-se ao fato de que a entidade divulga em seu Estatuto Social que os resultados devem ser destinados exclusivamente à consecução das finalidades sociais, não podendo ser, em qualquer hipótese, distribuídos aos associados (CASA DA CRIANÇA, 2011).

Tabela 06 - Teoria dos Fundos - ONG Casa da Criança (em Reais)

\begin{tabular}{|c|c|c|c|c|c|c|}
\hline & \multirow{2}{*}{$\begin{array}{c}\text { Uso irrestrito } \\
\text { Geral } \\
\end{array}$} & \multicolumn{3}{|c|}{ Uso internamente restrito } & \multirow{2}{*}{\begin{tabular}{|c}
$\begin{array}{c}\text { Uso } \\
\text { externamente } \\
\text { restrito }\end{array}$ \\
Doações \\
\end{tabular}} & \multirow{2}{*}{$\begin{array}{c}\text { Consolidado } \\
\text { TOTAL } \\
\end{array}$} \\
\hline & & imobilizado & social & soma & & \\
\hline ATIVO & & & & & & - \\
\hline
\end{tabular}




\begin{tabular}{|c|c|c|c|c|c|c|}
\hline Circulante & & & & - & & - \\
\hline Caixa e equivalentes & $72.870,88$ & & & - & & $72.870,88$ \\
\hline Direitos Realizáveis a Curto Prazo & $4.205,71$ & & & - & & $4.205,71$ \\
\hline Estoque de materiais para bazar & & & $1.843,06$ & $1.843,06$ & & $1.843,06$ \\
\hline Não circulante & & & & - & & - \\
\hline Imobilizado & & & & - & & - \\
\hline Edifícios & & $365.037,71$ & & $365.037,71$ & & $365.037,71$ \\
\hline Biblioteca & & $295.204,25$ & & $295.204,25$ & & $295.204,25$ \\
\hline Computadores e Periféricos & & $26.474,95$ & & 26.474,95 & & $26.474,95$ \\
\hline Instalações & & $18.866,66$ & & $18.866,66$ & & $18.866,66$ \\
\hline Máquinas e Equipamentos & & $11.639,83$ & & $11.639,83$ & & $11.639,83$ \\
\hline Móveis e utensílios & & $37.201,86$ & & $37.201,86$ & & $37.201,86$ \\
\hline Terrenos & & $18.566,99$ & & & & \\
\hline (-) Depreciação Acumulada & & $-\quad 102.916,83$ & & $\begin{array}{l}-\quad 102.916,83 \\
\end{array}$ & & $-\quad 102.916,83$ \\
\hline PASSIVO & & & & - & & - \\
\hline Circulante & & & & - & & - \\
\hline Salários e Ordenados a Pagar & 770,70 & & & - & & 770,70 \\
\hline Obrigações Tributárias & $1.766,35$ & & & - & & $1.766,35$ \\
\hline Outros créditos & $1.307,41$ & & & - & & $1.307,41$ \\
\hline PATRIMÔNIO SOCIAL & & & & - & & - \\
\hline Patrimônio social efetivado & & & & - & 642,22 & 642,22 \\
\hline Doações Patrimoniais & & & & - & $34.599,61$ & $34.599,61$ \\
\hline Reserva de reavaliação & & $180.623,84$ & & $180.623,84$ & & $180.623,84$ \\
\hline $\begin{array}{l}\text { Superávit do exercício } \\
\text { Superávit ou Déficit Exerc. }\end{array}$ & & & & $31.455,69$ & & $31.455,69$ \\
\hline Anteriores & & & $192.791,54$ & $192.791,54$ & & 192.791,54 \\
\hline TOTAL & $80.921,05$ & $850.699,26$ & $226.090,29$ & $1.058 .222,56$ & $35.241,83$ & $1.174 .385,44$ \\
\hline
\end{tabular}

\subsection{Demonstrativos iniciais e aplicação das Teorias - ONG Centro de Ação Voluntária}

Os Quadros 04 e 05 indicam os demonstrativos da ONG Centro de Ação Voluntária.

Quadro 04 - Balanço Patrimonial - ONG Centro de Ação Voluntár
\begin{tabular}{|l|r|}
\hline \multicolumn{1}{|c}{ ATIVO (Reais) } & \multicolumn{1}{|c|}{$\mathbf{2 . 0 0 7}$} \\
Circulante & $\mathbf{2 8 3 . 4 8 3 , 1 1}$ \\
Caixa e equivalentes & $278.530,76$ \\
Outros Créditos & $4.952,35$ \\
Adiantamentos de Ferias & $4.636,02$ \\
IRRF a compensar & 247,34 \\
PIS a compensar & 68,99 \\
& \\
Não circulante & $\mathbf{1 3 . 0 9 4 , 6 2}$ \\
Imobilizado & $13.094,62$
\end{tabular}

R. Cont. Ufba, Salvador-Ba, v. 6, n. 2, p. 21-38, maio-agosto 2012 


\begin{tabular}{|l|r|}
\multicolumn{1}{|c|}{ Bens Permanentes } & $31.068,36$ \\
(-) Depreciação Acumulada & $17.973,74$ \\
Total do Ativo & $\mathbf{2 9 6 . 5 7 7 , 7 3}$ \\
\multicolumn{1}{|c}{ PASSIVO (Reais) } & $\mathbf{2 . 0 0 7}$ \\
Circulante & $\mathbf{9 4 . 9 7 5 , 0 0}$ \\
Fornecedores Diversos & 137,50 \\
Salarios a Pagar & $6.030,00$ \\
Obrigações Fiscais a Pagar & $1.177,55$ \\
Contribuições a Pagar & 77,63 \\
Recursos de Projetos & $84.300,00$ \\
Provisão de Férias & $2.436,22$ \\
Provisão de INSS s/Férias & 621,22 \\
Provisão de FGTS s/Férias & 194,88 \\
& \\
Patrimônio Social & $\mathbf{2 0 1 . 6 0 2 , 7 3}$ \\
Superávits/Déficits Acumulados & $187.249,65$ \\
Ajuste Exercicios Anteriores & $6.243,84$ \\
Superávit no exercício de 2007 & $8.109,24$ \\
& \\
Total Passivo e PL & $\mathbf{2 9 6 . 5 7 7 , 7 3}$ \\
\hline
\end{tabular}

Fonte: adaptado de Centro de Ação Voluntária (2011).

Conforme disposto no Balanço, esta ONG não disponibiliza diretamente a alocação dos recursos de doações, sendo necessária a análise conjunta com a Demonstração do Resultado do Exercício. Contudo, em seu site, a ONG coloca os Demonstrativos de 2007 como os mais atualizados.

Quadro 05 - Demonstração do Resultado do Exercício - ONG Centro de Ação Voluntária

\begin{tabular}{|l|r|}
\hline \multicolumn{1}{|c|}{ Operações continuadas (Reais) } & \multicolumn{1}{c|}{$\mathbf{2 . 0 0 7}$} \\
Receitas & $\mathbf{4 8 0 . 2 4 9 , 8 1}$ \\
Receitas de Mensalidades e Cursos & 730,00 \\
Receitas de Eventos & $148.488,17$ \\
Receitas de Programas & $93.500,00$ \\
Doações Recebidas & $217.200,00$ \\
(-) Repasse Outras Entidades & $-119.500,00$ \\
Projetos - Parceria & $30.000,00$ \\
Outras Receitas & 104,02 \\
& \\
Receitas Financeiras & $17.162,07$ \\
& \\
Variações Patrimoniais - benefícios & $95.936,71$ \\
\end{tabular}




\begin{tabular}{|l|r|}
\hline (-) Deduções da Receitas & \\
Imposto Sobre Serviços - ISS & - \\
Cofins s/Aplic Financeira & $-749,91$ \\
Pis s/Aplicacao Financeira & - \\
& \\
Despesas & $-\mathbf{4 7 2 . 1 4 0 , 5 7}$ \\
Despesas de Eventos & $-134.618,28$ \\
& \\
Despesas Administrativas & $-207.252,86$ \\
Despesas Com Pessoal - Salários e Benefícios & $-118.882,30$ \\
Despesas Com Pessoal - Encargos Sociais & $-50.242,25$ \\
Despesas Gerais & $-37.533,56$ \\
Outras Despesas & - \\
& \\
Despesas Financeiras & $\mathbf{5 . 1 0 9 , 2 4}$ \\
\hline
\end{tabular}

Fonte: adaptado de Centro de Ação Voluntária (2011).

No Quadro 05 dispõem-se os valores recebidos pela entidade e efetivamente aplicados na manutenção de suas atividades. A partir destes dados iniciais, é possível realizar algumas reclassificações e analisar como as Teorias dos Direitos de Propriedade elencadas aplicam-se no segmento representado.

A Tabela 07 demonstra os valores obtidos para a ONG Centro de Ação Voluntária, indicando os recursos que a entidade possui a disposição dos proprietários, segundo a Teoria do Proprietário.

Tabela 07 - Teoria do Proprietário - ONG Centro de Ação Voluntária (em Reais)

\begin{tabular}{l|r|l|r}
\hline ATIVO & $\mathbf{2 9 6 . 5 7 7 , 7 3}$ & PASSIVO & $\mathbf{9 4 . 9 7 5 , 0 0}$ \\
\hline Circulante & $283.483,11$ & Circulante & $94.975,00$ \\
Não Circulante & $13.094,62$ & Não Circulante & 0,00 \\
ATIVO - PASSIVO $=$ & $201.602,73$ (PROPRIETÁRIO) & \\
\hline \multicolumn{2}{c}{ Fonte: elaborado pelos autores. }
\end{tabular}

Já a Tabela 08 demonstra os valores obtidos conforme a Teoria da Entidade para a ONG Centro de Ação Voluntária, representando os valores que correspondem à empresa.

Tabela 08 - Teoria da Entidade - ONG Centro de Ação Voluntária (em Reais)

\begin{tabular}{l|r|l|r}
\hline ATIVO & $\mathbf{2 9 6 . 5 7 7 , 7 3}$ & PASSIVO & $\mathbf{2 9 6 . 5 7 7 , 7 3}$ \\
\hline Circulante & $283.483,11$ & Circulante & $94.975,00$ \\
Não Circulante & $13.094,62$ & Não Circulante & 0,00 \\
& & PATRIMÔNIO LÍQUIDO & $\mathbf{2 0 1 . 6 0 2 , 7 3}$ \\
\hline
\end{tabular}

Fonte: elaborado pelos autores. 
A Tabela 09 representa os valores da ONG Centro de Ação Voluntária, alocados conforme a Teoria dos Fundos. Considerou-se como Uso Irrestrito as rubricas que não possuíam destinação específica, conforme informações em Estatuto Social. Já as contas de Uso Internamente Restrito representam os valores que serão alocados somente em imobilizados da empresa, ou sem atividades de cunho social, tais como os projetos geridos pela organização. Já a coluna de Uso Externamente Restrito representa o valor total dos recursos elencados no Patrimônio Líquido, pois, conforme Estatuto Social, toda a renda, recursos e eventual resultado operacional serão aplicados integralmente para a manutenção e desenvolvimento dos objetivos e finalidades da ONG, a saber, promover programas especializados de apoio ao primeiro, segundo e terceiro setores, relacionados à cidadania e ao voluntariado e promover e elaborar projetos, profissionalizantes ou não, nas áreas social, educacional, de saúde, cultural, esportiva, ambiental e de sustentabilidade que atendam demandas com o trabalho voluntário (CENTRO DE AÇÃO VOLUNTÁRIA, 2011).

Tabela 09 - Teoria dos Fundos - ONG Centro de Ação Voluntária (em Reais)

\begin{tabular}{|c|c|c|c|c|c|c|}
\hline & Uso irrestrito & Uso i & ternamente & strito & $\begin{array}{l}\text { Uso externamente } \\
\text { restrito }\end{array}$ & Consolidado \\
\hline & Geral & imobilizado & social & soma & Sustentabilidade & TOTAL \\
\hline ATIVO & & & & - & & - \\
\hline Circulante & & & & - & & - \\
\hline Caixa e equivalentes & $278.530,76$ & & & - & & $278.530,76$ \\
\hline Outros Créditos & $4.952,35$ & & & - & & $4.952,35$ \\
\hline Adiantamentos de Ferias & $4.636,02$ & & & - & & $4.636,02$ \\
\hline IRRF a compensar & 247,34 & & & - & & 247,34 \\
\hline PIS a compensar & 68,99 & & & - & & 68,99 \\
\hline Não circulante & & & & - & & - \\
\hline Imobilizado & & & & - & & - \\
\hline Bens Permanentes & & $31.068,36$ & & $31.068,36$ & & $31.068,36$ \\
\hline (-) Depreciação Acumulada & & $-17.973,74$ & & $-\quad 17.973,74$ & & - $\quad 17.973,74$ \\
\hline PASSIVO & & & & - & & - \\
\hline Circulante & & & & - & & - \\
\hline Fornecedores Diversos & 137,50 & & & - & & 137,50 \\
\hline Salarios a Pagar & $6.030,00$ & & & - & & $6.030,00$ \\
\hline Obrigações Fiscais a Pagar & $1.177,55$ & & & - & & $1.177,55$ \\
\hline Contribuições a Pagar & 77,63 & & & - & & 77,63 \\
\hline Recursos de Projetos & & & $84.300,00$ & $84.300,00$ & & $84.300,00$ \\
\hline Provisão de Férias & $2.436,22$ & & & - & & $2.436,22$ \\
\hline Provisão de INSS s/Férias & 621,22 & & & - & & 621,22 \\
\hline Provisão de FGTS s/Férias & 194,88 & & & - & & 194,88 \\
\hline PATRIMÔNIO SOCIAL & & & & - & & - \\
\hline Superávits/Déficits Acumulados & & & & - & $187.249,65$ & $187.249,65$ \\
\hline Ajuste Exercicios Anteriores & & & & - & $6.243,84$ & $6.243,84$ \\
\hline Superávit no exercício de 2007 & & & & - & $8.109,24$ & $8.109,24$ \\
\hline
\end{tabular}


No caso das ONG, acredita-se que a Teoria da Entidade é mais adequada que a Teoria do Proprietário, já que esta última aufere os direitos e obrigações da entidade a um grupo restrito de pessoas, no caso os proprietários. Assim, a Teoria da Entidade parece estar mais de acordo com o objeto social da ONG, que presta serviços para a sociedade como um todo, e não privilegia um grupo restrito de indivíduos detentores do Capital Social.

Conforme observa-se pelas Tabelas 03, 06 e 09, a Teoria dos Fundos pode ser aplicada às três organizações analisadas, tornando-se mais um item de transparência e fornecendo suporte à tomada de decisão, um dos objetivos das demonstrações financeiras.

\section{CONSIDERAÇÕES FINAIS}

Inicialmente pode-se destacar, segundo Iudícibus (2010, p.178) que "várias teorias explicativas do patrimônio líquido (ou de sua natureza) são disponíveis, cada uma com seus méritos e limitações e nenhuma podendo fornecer a base completa de explicação". Esta afirmação serve para complementar o resultado desta pesquisa que teve por intenção analisar a aplicabilidade das teorias do proprietário, da entidade e do fundo em empresas sem fins lucrativos.

A questão de pesquisa foi respondida após a transformação dos dados coletados em informações úteis para acionistas e administradores sob a ótica das teorias do patrimônio líquido estudadas, e mais especificamente na adaptação das demonstrações financeiras utilizando-se das propostas da teoria dos fundos.

É possível a aplicação da teoria do proprietário, da teoria da entidade e da teoria do fundo em empresas sem fins lucrativos. Pode-se inferir da aplicação das teorias elencadas que há como identificar o patrimônio líquido pela ótica de cada uma das teorias, para as empresas estudadas.

Após a confecção do balanço conforme a teoria dos fundos, onde os dados patrimoniais são expostos de maneira diferenciada, foi possível inferir da pesquisa que a elaboração deste balanço é útil para empresas sem fins lucrativos. O valor final de patrimônio líquido não altera entre as teorias, porém a visão da teoria dos fundos apresenta um detalhamento dos recursos recebidos e suas respectivas aplicações. Tal detalhamento é importante para empresas sem fins lucrativos, para aperfeiçoar sua evidenciação, e sua utilização pode ser mais um critério de transparência para as empresas, aumentando sua credibilidade.

Este estudo é limitado principalmente pela quantidade de empresas analisadas, e disponibilidade de dados para avaliação da aplicabilidade das teorias elencadas, contudo, serve como possibilidade para outros estudos da área.

A importância deste estudo se deve a percepção de que empresas sem fins lucrativos podem ser observadas também pela ótica da Teoria do Proprietário e da Entidade, não somente sendo utilizada a Teoria do Fundo. Contudo, esta é a que melhor reflete as informações necessárias e úteis para visualização dos fundos. E é importante reconhecer que se há disponível tal ferramenta para demonstrar as atividades destas empresas, é imprescindível que sejam utilizadas e reconhecidas. 


\section{REFERÊNCIAS}

ABE, César Henrique Shogi. Teorias contábeis sobre o patrimônio líquido e teoria da renda-acréscimo patrimonial: um estudo interdisciplinar. Dissertação de mestrado FEA/USP, 2007.

AMERICAN INSTITUTE OF CERTIFIED PUBLIC ACCOUNTANTS. Statement Financial Accounting Standards $\mathrm{n}^{\circ} 117$. Financial Statement of Nor-for-profit organizations. Financial Accounting Standards Board. June, 1993.

CASA DA CRIANÇA. Disponível em: http://casa-da-crianca.blogspot.com/2009/06/balancopatrimonial-e-dre.html. Acesso em: 21/11/2011.

CENTRO DE AÇÃO VOLUNTÁRIA. Disponível em:

http://www.acaovoluntaria.org.br/mostraConteudo.asp?id=4. Acesso em: 21/11/2011.

CPC - Comitê de Pronunciamentos Contábeis. Disponível em: www.cpc.org.br.

HANSMANN, H. The role of nonprifit enterprise. Yale law Journal. New Haven.

Connecticut. V. 15. N. 89. P. 835-901. 1980.

HENDRIKSEN, Eldon S.; VAN BREDA, Michael F. Teoria da Contabilidade. São Paulo: Atlas, 2007.

IUDÍCIBUS, Sérgio de. Teoria da Contabilidade. 10. ed. São Paulo: Atlas, 2010.

IASB, International Accounting Sandards Board. Normas Internacionais de Contabilidade. São Paulo: IBRACON, 2001.

KAM, Vernon. Accounting Theory. Ney York: John Wiley \& Sons, 1986.

PARCEIROS VOLUNTÁRIOS. Disponível em: http://www.parceirosvolu ntarios.org.br/componentes/parceiros/ParceirosVoluntarios.asp. Acesso em: 02/11/2011.

SAMPIERI, Roberto Hernández; COLLADO, Carlos Fernández; LUCIO, Pilar Baptista. Metodologia de pesquisa. 3. ed. São Paulo: McGraw-Hill, 2006.

SANTANA, Gislaine Aparecida da Silva; PAULA, Cleberson Luiz Santos de; OLIVEIRA, Gideão José Pinto; COLAUTO, Romualdo Douglas. Teoria da Entidade versus Teoria dos Fundos: uma análise da evidenciação das demonstrações financeiras de uma organização sem fins lucrativos. XV Congresso Brasileiro de Custos - Curitiba/PR, Brasil, 12 a 14 de novembro de 2008.

STAUBUS, George J. The residual equity point of view in accounting. The Accounting Review, vol. 34, p. 3-13, jan/1959. 